\title{
Household Food Insecurity and Hunger in Selected Ethiopian Agricultural Communities: Examination of Supply and Demand Factors
}

\author{
Getahun Ersino $^{1,2}$, Gordon A. Zello ${ }^{1}$, Carol J. Henry ${ }^{1}$ \& Nigatu Regassa ${ }^{1}$ \\ ${ }^{1}$ College of Pharmacy and Nutrition, University of Saskatchewan, Saskatoon, Canada \\ ${ }^{2}$ School of Nutrition, Food Science and Technology, Hawassa University, Hawassa, Ethiopia \\ Correspondence: Getahun Ersino, College of Pharmacy and Nutrition, University of Saskatchewan, Health \\ Sciences, 104 Clinic Place, Saskatoon, SK, S7N 2Z4. Canada. Tel: 1-306-966-1151. E-mail: \\ getahun.lombamo@usask.ca
}

$\begin{array}{lc}\text { Received: April 2, } 2018 & \text { Accepted: April 20, } 2018 \quad \text { Online Published: June 5, } 2018 \\ \text { doi:10.5539/jfr.v7n4p107 } & \text { URL: https://doi.org/10.5539/jfr.v7n4p107 }\end{array}$

\begin{abstract}
Food insecurity and hunger are major challenges in many Ethiopian communities with repercussions on health and nutrition outcomes in vulnerable household members. The level and contextual risk factors of household food insecurity and hunger were assessed in households $(n=630)$ from three rural communities of Ethiopia (Halaba or Zeway) using the Household Food Insecurity Access Scale and Household Hunger Scale. Multiple classification analysis was employed to explore the effects of key demand (e.g. household size, livestock) and supply (e.g. land size, frequency of production) factors and community (geographic location) as well as institutional (participation in food security programs) factors on food insecurity and hunger. Household food insecurity was unacceptably high in both districts (95\% in Halaba \& $67 \%$ in Zeway). Household hunger was $38 \%$ in Halaba and $18 \%$ in Zeway. Both food insecurity and hunger were significantly greater in Halaba $(p<0.001)$, indicating an effect of geographic location. Both supply and demand factors were significant in determining household food insecurity and hunger $(\mathrm{p}<0.01)$; however, supply factors such as women's access to land, land size and wealth had greater influence than the demand factors. Levels of food insecurity and hunger in both communities were very high and of serious concern. We recommend increasing the food supply, and its subsequent accessibility, for households through enhancing women's access to land, improving income through savings and wealth accumulation, introducing more inclusive programs for women's participation and reducing household work-burden by significantly enhancing productivity of cultivable land.
\end{abstract}

Keywords: household food insecurity, household hunger, demand-supply factors, Ethiopia

\section{Introduction}

Food security is complex as it is multidimensional. As such the definitions of food security have evolved through the decades from a national level food supply emphasis to household level food access and individual level utilization (Smith, Pointing, \& Maxwell, 1992). One definition adopted by the 1996 World Food Summit states "food security exists when all people, at all times, have physical, social and economic access to sufficient, safe and nutritious food which meets their dietary needs and food preferences for an active and healthy life" (FAO, 1996). Based on this definition, the partial or complete absence of these conditions at household level may lead to household food insecurity or even household hunger, in severe situations.

Ethiopia is among the many sub-Saharan African and other low-income countries experiencing household food insecurity and hunger at various times during a given year (Ali et al., 2013; Deitchler, Ballard, Swindale, \& Coates, 2010; Endale, Mengesha, Atinafu, \& Adane, 2014; Regassa, 2011; Regassa \& Stoecker, 2012). The vulnerability to food insecurity in Ethiopia is exacerbated, in part, by its heavy dependence on small scale, mostly low-input, rain-fed agriculture (Devereux, 2000) which supports the livelihood of over 85\% of the population (Central Statistical Agency [of Ethiopia], 2015). Several studies in different parts of Ethiopia have reported on the prevalence of household food insecurity and its negative nutritional consequences on vulnerable household members (Ali et al., 2013; Anderson, Tegegn, Tessema, Galea, \& Hadley, 2012; Belachew, Lindstrom, 
Gebremariam, et al., 2013; Belachew et al., 2012; Belachew, Lindstrom, Hadley, et al., 2013; Hadley, Tessema, $\&$ Muluneh, 2012; Roba et al., 2015). Though food insecurity is generally considered a characteristic of the rural poor, high rates of food insecurity were also documented in urban settings (Birhane, Shiferaw, Hagos, \& Mohindra, 2014; Kimani-Murage et al., 2014).

Often food insecurity is a socioeconomic condition in which households of low-socioeconomic status have limited economic access to sufficient and quality foods for all family members throughout the year. Previous household level studies documented factors such as household size, land size, educational status, headship, access to credit services, agricultural extension packages as key predictors of household food security status (Belachew et al., 2012; Birhane et al., 2014; Endale et al., 2014; Regassa, 2011; Sewnet, 2015). These and other similar factors such as women's access to land, work burden on women, frequency of production per year and livestock ownership could be summarised as demand or supply side factors at household level. Demand side factors (such as household size, livestock ownership) generally affect households' ability to access adequate food while supply side factors (such as land size and frequency of production) mainly affect the food supply. Despite some attempts (Alem, 2013; Feleke, Kilmer, \& Gladwin, 2005) evidence is limited whether household food insecurity is more a function of demand or supply side factors, or a combination of both, at the household level in rural Ethiopia.

While several tools are available, the Food and Nutrition Technical Assistant project (FANTA) of the United States Agency for International Development (USAID) introduced a Household Hunger Scale (HHS) in 2011 as a method to measure a more severe form of food insecurity at household level (Deitchler, Ballard, Swindale, \& Coates, 2011). Unlike the commonly used Household Food Insecurity Access Scale (HFIAS), the HHS has been validated for cross-cultural use allowing comparison of findings across various regions within and between countries (Deitchler et al., 2010). We were unable to find studies that applied the HHS to estimate household hunger in rural Ethiopia, except for two studies (Regassa, 2011; Regassa \& Stoecker, 2012). These previous studies did not, however, assess whether food insecurity and hunger were a function of demand or supply side factors at household level.

Therefore, we measured household food insecurity and hunger in the agricultural communities of Halaba and Zeway in Ethiopia, using both HFIAS and the new HHS, and determined whether demand or supply or a combination of both, at household levels predicted vulnerability to household food insecurity and hunger. The decision to use both tools was to enable us to compare our results with previous studies that utilized the HFIAS and the few studies that used the new HHS in similar settings. The study sites, selected based on their farming practices, were part of a larger collaborative research project between Hawassa University (Ethiopia) and the University of Saskatchewan (Canada) that sought to improve food security and human nutrition through improving agricultural practices in these areas.

\section{Methods}

The study was conducted in three rural communities located in two adjacent administrative regions of Ethiopia. Two of the three communities (locally known as Guba-Sherero and Holagoba-Kukie) were part of the Halaba district, located in the Southern Nations and Nationalities and People's Region (SNNPR). Halaba district is located approximately 85 kilometers northwest of Hawassa, the capital of SNNPR. The district is known for growing pepper and pulses, both of which are considered cash crops for the farmers. Rain-fed agriculture is the main livelihood. The third rural community (locally known as Edo-Qontola) is located near the town of Zeway and is part of Adami-Tulu-Jido-Kombolcha district in the Oromiya Region. It is located approximately 160 kilometers southeast of Addis Ababa, Ethiopia's capital. Maize, teff, wheat, barley and different oil seeds are the major crops produced in the district. The area is mostly dry land, and both irrigated and rain-fed agriculture are practiced.

A total of 630 households (413 from Halaba and 217 from Zeway communities) were selected to participate in this study using simple random sampling. Ten data collectors met at the central location of each community and randomly walked in different directions to individual households. Households were selected based on whether they had at least one $<5 y$ rs of age child (to enable us conduct other mother-child nutrition specific studies) until the sample size was achieved. Sample size was determined using formula for cross-sectional studies (Charan \& Biswas, 2013), assuming the $27 \%$ probability of maternal undernutrition reported at national level (Central Statistical Agency [Ethiopia] and ICF International, 2012). The respondents were women (mothers) in the selected households as they were mostly responsible for the procurement, preparation and serving of meals, and hence were well informed about the food supply situation of the household. Data were collected between the months of March and June. 
The women were interviewed by trained female data collectors who had some post-secondary education and spoke the local languages fluently. The data collection was supervised by an investigator (GE) and a research assistant who also spoke the local language fluently. Background characteristics of participating households were collected by a translated questionnaire adapted from previous national and local survey studies in the regions (EHNRI, 2010; Roba et al., 2015; Tessema, Belachew, \& Ersino, 2013). Information collected included household size, age of respondents, headship of households, size of cultivable land, women's access to land, person in charge of production (men or women or both men and women), frequency of cultivation of food crops per year, occupation of mothers and their husbands, information on livestock, various household assets, housing characteristics (types of floor, roof, window materials), sanitation facility, source of drinking water, persons mainly responsible for hauling water and the time required per trip, and household's involvement in any food security programs in their respective administrative districts.

These background characteristics were used directly or as proxy measures to generate various supply and demand related factors that may affect household food insecurity and hunger. Fetching water is mostly the responsibility of women. It takes time away from other productive activities (e.g. working on farm, cash earning activities) and adds to the work burden of women since water sources are not available on premises (WHO \& UNICEF, 2010). Hence, time required to fetch water ( $<30$ minutes/trip or $\geq 30$ minutes/trip) was used as a proxy to measure presence of work burden on women (BOWYCA, 2013; WHO \& UNICEF, 2010). In this case a single trip requiring half hour, or more, was taken as indicator of presence of work burden. We also calculated physiological density (the ratio of number of persons in the household [that needs to be fed] to unit of cultivable land owned by the household) and households were classified as above or below the average $(\leq 8$ or $>8)$. Livestock information was used to calculate Tropical Livestock Units (TLU). One TLU is the equivalence of $250 \mathrm{~kg}$ of livestock owned by the household (Storck, Emana, Adinew, Borowiecki, \& W/Hawariat, 1991). Households were grouped as having low $(<2.5)$, medium $(2.5-5)$ or high $(>5)$ TLU, using the mean TLU value (i.e. below mean, mean to twice the mean, and above twice the mean). Wealth index for each household was also generated using household assets (i.e. ownership of radio, television, mobile phone, bicycle, animal drawn cart, motorcycle, handheld torch, and oxen), housing characteristics (i.e. corrugated iron or thatched grass roof, cow dung smeared/cemented or earth/dirt floor, presence or absence of windows, crowding [persons per sleeping room $>5$ or $\leq 5]$ ) and access to improved sanitation. Scores 1 or 0 were assigned for each household based on ownership of each asset or housing characteristics or access to improved sanitation facility. Then households were grouped into three of wealth index as low $(<4)$, medium (4-8) and high $(>8)$, following similar procedure as the TLU groups.

Degree and prevalence of household food insecurity were assessed using a translated scale developed by the Food and Nutrition Technical Assistance (FANTA) project of United States Agency for International Development (USAID) for use in developing countries (Coates, Swindale, \& Bilinsky, 2007). The Household Food Insecurity Access Scale (HFIAS), version 3, is administered with a recall period of four weeks. Several food security studies in Ethiopia have used this tool (Belachew, Lindstrom, Gebremariam, et al., 2013; Birhane et al., 2014; Endalew, Muche, \& Tadesse, 2015; Regassa \& Stoecker, 2012). It contains nine main items followed by frequency questions (i.e. 1. rarely, 2. sometimes, and 3. often) completed for every affirmative response in the main item. If each household were to respond affirmatively to the nine items of HFIAS with a frequency of occurrence of '3. often', then there would be a maximum possible score of 27 for each household that responded to all the nine items of the scale. A score closer to zero indicates absence of food insecurity and a score closer to 27 means greater degree of food insecurity. The nine items in HFIAS are arranged to measure increasing severity of occurrence, with the last three indicating severe conditions of household food insecurity. Utilizing the last three main items from HFIAS, FANTA also introduced a simple scale called Household Hunger Scale (HHS) (Deitchler et al., 2011). The HHS was intended to identify proportions of households at different levels of household hunger and was validated for cross-cultural comparison (Deitchler et al., 2011). The scores on HHS range from 0-6, with higher scores representing increasing severity of household hunger. Studies (Regassa and Stoecker 2012, Regassa 2011) have used this tool in similar Ethiopian communities. Therefore, HHS was also used to estimate prevalence of household hunger.

All questionnaire responses were inspected at field level. The data were entered in a SPSS spreadsheet (SPSS Statistics Version 20, IBM Corp., Armonk, NY, USA), previously prepared based on each item and response options on the questionnaire. Mean, standard deviation, median, percentile values (25th, 75th) and percentages were used to present findings from univariate and bivariate analysis. Results from HFIAS were presented as percent of households with affirmative responses to each of the nine main items and average degree of food insecurity and hunger in each community were expressed as median scores and percentile values (25th, 75 th). 
Median scores were compared using Mann Whitney U-test. In addition, using the HFIAS guide (Coates et al. 2007), households were grouped using summary measures of the scale as food secure, or insecure (i.e. mildly or moderately or severely food insecure). Households were also classified as having 'little to no household hunger' or 'moderate household hunger' or 'sever household hunger' based on HHS (Deitchler et al., 2011). Categorical variables were compared between communities using Chi-square test.

In the multivariate analysis, a combination of selected demand (i.e. number of children under 5 yrs of age per household, physiological density, household TLU, wealth index) and supply-side (women's access to land, work burden on women, household land size, frequency of crop production per year,) as well as community variable (being in Halaba or Zeway area, as proxy to the farming practices) and institutional variable (participation in any food security programs in the district) were used as explanatory factors. The selection of these factors was based on previous studies (Alem, 2013; Belachew et al., 2012; Birhane et al., 2014; Endale et al., 2014; Feleke et al., 2005; Regassa, 2011; Sewnet, 2015). Scores for degree of household food insecurity and household hunger in the pooled data from the two districts were used as dependent (outcome) variables in two separate models. A Multiple Classification Analysis (MCA) was used to present the mean of the dependent variables across each level of the selected categorical predictor variables (Nagpaul, 1999). Both unadjusted and adjusted mean scores along with their associated Eta $(\eta)$ and Beta $(\beta)$ values were reported, respectively. Eta indicates the bivariate association between a predictor and the dependent variable whereas beta indicates the relationship of a predicator variable to the dependent variable in the multivariate model, keeping all other predictors constant (Nagpaul, 1999). Beta also signifies the relative importance of the variable in predicting variation in the dependent variable while the square of Eta signifies the amount of variation explained by all categories of the predictor. $F$-values are reported for each model with the degrees of freedom, the associated $R^{2}$ and $P$-values. A $P$-value of $<0.05$ was used to determine statistical significance.

\section{Ethical standard disclosure:}

This study was conducted according to the guidelines laid out in the Declaration of Helsinki and all procedures involving human subjects were approved by the University of Saskatchewan Behavioral Ethics Board (BEH \#12-357) and the Regional Health Bureaus of SNNPR and Oromiya. Verbal informed consent was obtained from all subjects. Verbal consent was witnessed and formally recorded.

\section{Results}

\subsection{Background Characteristics}

Most households completed all background questions. One household from Zeway community did not complete the food security assessment, hence the results were presented for a total of 629 households out of the 630 selected. The communities were similar on most background characteristics, such as household size, number of $<5 y r s$ of age children, headship, occupation of men and women, ownership of livestock, toilet facility, person responsible for hauling water. Significant differences were observed between the communities in the size of cultivable land, enset plant (Note 1) ownership, source of drinking water and time required to fetch water $(\mathrm{P}<0.001)$. 
Table 1. Individual and household related background characteristics of study participants from Halaba and Zeway rural districts, Ethiopia, 2013

\begin{tabular}{|c|c|c|c|c|}
\hline Background characteristics & Halaba & Zeway & Combined & $P$-values" \\
\hline Household (HH) size & $\mathrm{n}=413$ & $\mathrm{n}=217$ & $\mathrm{n}=630$ & \\
\hline Mean $( \pm$ SD $)$ & $5.9(1.9)$ & $6.3(2.2)$ & $6(2)$ & \\
\hline Number of children $<5$ yrs per $\mathrm{HH}(\%)$ & $\mathrm{n}=413$ & $\mathrm{n}=213$ & $\mathrm{n}=630$ & \\
\hline One & 56.2 & 61.8 & 58.1 & \\
\hline Two & 41.4 & 35 & 39.2 & \\
\hline Three or more & 2.4 & 3.2 & 2.7 & \\
\hline Head of household (\%) & $\mathrm{n}=413$ & $\mathrm{n}=217$ & $\mathrm{n}=630$ & \\
\hline Women/wife & 9.9 & 7 & 8.9 & \\
\hline Husband & 90.1 & 93 & 91.1 & \\
\hline HH cultivated land size $(\%)$ & $\mathrm{n}=396$ & $\mathrm{n}=199$ & $\mathrm{n}=595$ & \\
\hline$\leq 0.5$ hectare & 33.8 & 23.1 & 30.3 & $<0.05$ \\
\hline $0.6-1.0$ hectare & 40.9 & 40.7 & 40.8 & \\
\hline$>1.0$ hectares & 25.3 & 36.2 & 28.9 & \\
\hline Ownership of enset (E. ventricosum) plant (\%) & $\mathrm{n}=407$ & $\mathrm{n}=214$ & $\mathrm{n}=621$ & \\
\hline Yes & 8.8 & 1.4 & 6.1 & $<0.001$ \\
\hline Women's main occupation (\%) & $\mathrm{n}=413$ & $\mathrm{n}=217$ & $\mathrm{n}=630$ & \\
\hline Housewife & 93.5 & 89.4 & 92.1 & \\
\hline Petty trading & 4.1 & 5.1 & 4.4 & \\
\hline Others $^{1}$ & 2.4 & 5.5 & 3.5 & \\
\hline Husband's main occupation (\%) & $\mathrm{n}=413$ & $\mathrm{n}=217$ & $\mathrm{n}=630$ & \\
\hline Farmer & 90 & 89.7 & 87.6 & \\
\hline Other $^{1}$ & 10 & 10.3 & 12.4 & \\
\hline HH ownership of domestic animals (\%) & $\mathrm{n}=413$ & $\mathrm{n}=216$ & $\mathrm{n}=629$ & \\
\hline Yes & 84.7 & 82.4 & 83.9 & \\
\hline HH toilet facility (\%) & $\mathrm{n}=413$ & $\mathrm{n}=217$ & $\mathrm{n}=630$ & \\
\hline No toilet facility & 26.6 & 35 & 29.5 & \\
\hline Traditional pit latrine & 17.4 & 15.2 & 16.7 & \\
\hline Pit latrine with shade & 55.8 & 49.3 & 53.5 & \\
\hline Ventilated improved pit latrine & 0.2 & 0.5 & 0.3 & \\
\hline Source of drinking water $(\%)$ & $\mathrm{n}=413$ & $\mathrm{n}=217$ & $\mathrm{n}=630$ & \\
\hline Public tab/stand pipe & 95.9 & 47 & 82.3 & $<0.001$ \\
\hline Protected well & 0 & 43.8 & 15.1 & \\
\hline Other $^{2}$ & 4.1 & 9.2 & 2.6 & \\
\hline Person responsible for fetching water $(\%)$ & $\mathrm{n}=413$ & $\mathrm{n}=217$ & $\mathrm{n}=630$ & \\
\hline Women & 69 & 65 & 67.6 & \\
\hline Others $^{3}$ & 31 & 35 & 32.4 & \\
\hline Time (minutes) required to fetch water (\%) & $\mathrm{n}=404$ & $\mathrm{n}=216$ & $\mathrm{n}=630$ & \\
\hline$<30$ minutes & 20.1 & 43.8 & 28.3 & $<0.001$ \\
\hline $30-60$ minutes & 35.6 & 23.5 & 31.4 & \\
\hline$>60$ minutes & 44.3 & 32.7 & 40.3 & \\
\hline $\operatorname{Median}\left(25^{\text {th }}, 75^{\text {th }}\right)$ & $60(30,120)$ & $30(10,120)$ & $60(20,120)$ & \\
\hline
\end{tabular}

$\mathrm{HH}$, Household; ${ }^{1} \mathrm{Other}=$ civil servant, agricultural labourer, tenant farmer, daily labourer; ${ }^{2}$ Surface water (river, lake, pond, etc.), unprotected well $;{ }^{3}$ men, children, maid, rented donkey cart; ${ }^{*} P$-values were for comparison of study sites using Chi-square tests;

\subsection{Estimation of Household Food Insecurity and Household Hunger}

Tables 2 and 3 present the food security situation of households classified using HFIAS and HHS scales. Affirmative responses to each of the nine occurrence items (Table 2) were twice or three times more in Halaba than Zeway households $(P<0.001)$. In addition, the median score of HFIAS and HHS were significantly higher for Halaba than Zeway study households $(P<0.001)$. 
Table 2. Percentage of affirmative responses to the HFIAS and HHS occurrence items and median scores of households from rural Halaba or Zeway in the four weeks preceding the interview during March-June 2013

\begin{tabular}{lllll}
\hline Indicators (occurrence items) \% & Halaba & Zeway & Combined & $P$-values \\
\hline & $\mathrm{n}=413$ & $\mathrm{n}=216$ & $\mathrm{n}=629$ & \\
Worry that the household would not have enough food & 72.9 & 35.6 & 60.1 & $<0.001$ \\
Not able to eat the kinds of food preferred & 82.1 & 54.2 & 72.5 & $<0.001$ \\
Eat a limited variety of foods & 82.3 & 54.6 & 72.8 & $<0.001$ \\
Eat some foods that you really did not want to eat & 78.0 & 46.3 & 67.1 & $<0.001$ \\
Eat a smaller meal than you felt you needed & 75.3 & 43.1 & 64.2 & $<0.001$ \\
Eat fewer meals in a day & 69.7 & 36.6 & 58.3 & $<0.001$ \\
No food to eat of any kind in your household & 56.2 & 14.8 & 42.0 & $<0.001$ \\
Go to sleep at night hungry & 39.5 & 20.4 & 32.9 & $<0.001$ \\
Go a whole day and night without eating & 25.7 & 12.0 & 21.0 & $<0.001$ \\
& & & & \\
Median score $\left(25^{\text {th }}\right.$, 75 & & & & \\
HFIAS & $11(6,16)$ & $3(0,8)$ & $8(3,14)$ & $<0.001$ \\
HHS & $1(0,3)$ & $0(0,0)$ & $0(0,2)$ & $<0.001$ \\
\hline
\end{tabular}

HFIS, Household Food Insecurity Access Scale; HHS, Household Hunger Scale; * $P$-values were for comparison of study sites using Chi-square tests for proportions and Mann-Whitney $U$-test (2-tailed) for median scores.

Summary measures of HFIAS and HHS are presented in Table 3. Only 15\% of households in the pooled data were food secure. A significant majority of Halaba households (63\%) were classified as severely food insecure compared with only $21 \%$ in Zeway $(\mathrm{P}<0.001)$. Likewise, the classification of the households based on the newly developed HHS showed nearly $31 \%$ of all households experienced moderate to severe levels of hunger. Proportion of households that experienced both levels of hunger were twice as large in Halaba as those in Zeway $(\mathrm{P}<0.001)$. No participant household from the Zeway community fell in the category of 'severe household hunger' whereas $13 \%$ did in the Halaba.

Table 3. Prevalence of household food insecurity and household hunger based on HFIAS and HHS during the four weeks prior to the interview day between March-June 2013 in rural Halaba or Zeway, Ethiopia

\begin{tabular}{lllll}
\hline & Halaba & Zeway & Combined & $P$-values \\
\hline & $\mathrm{n}=413$ & $\mathrm{n}=216$ & $\mathrm{n}=629$ & \\
$\quad$ & & & & \\
Summary measures of HFIAS & 5.3 & 33.3 & 14.9 & $<0.001$ \\
$\quad$ Food secure & 94.7 & 66.7 & 85.1 & \\
$\quad$ Food insecure & 10.4 & 16.7 & 12.6 & \\
$\quad$ Mildly food insecure & 20.8 & 28.7 & 23.5 & \\
$\quad$ Moderately food insecure & 63.4 & 21.3 & 49.0 & \\
$\quad$ Severely food insecure & & & & \\
$\quad$ Summary Measures of HHS & 62.2 & 82.4 & 69.2 & $<0.001$ \\
$\quad$ Little or no household hunger & 37.8 & 17.6 & 30.8 & \\
$\quad$ Household hunger & 24.9 & 17.6 & 22.4 & \\
$\quad$ Moderate household hunger & 12.9 & 0 & 8.4 & \\
$\quad$ Sever household hunger & 12.9
\end{tabular}

HFIAS, Household Food Insecurity Access Scale; HHS, Household Hunger Scale; ${ }^{*} P$-values were for comparison of study sites using Chi-square tests.

\subsection{Multivariate Analysis: Demand-supply Factors as Predictors of Household Food Insecurity and Hunger}

Tables 4 and 5, respectively, present findings from the Multiple Classification Analysis using scores from the HFIAS and HHS as dependent variables. Each of the selected demand-supply side factors significantly predicted degree of household food insecurity in the study households (Table 4) and the overall model explained significant variation in the dependent variable $\left[F(14)=26.624, P<0.001 ; \mathrm{R}^{2}=0.405\right]$. Mean scores for degree of food insecurity were significantly different among the levels of each of the identified demand related factors (i.e. number of children under 5yrs of age per household, physiological density household TLU and household wealth). More children under 5yrs of age, higher physiological density low TLU and lower wealth index were associated with a higher degree of food insecurity, after adjustment for other factors in the model. Likewise, supply side factors (i.e. women with no access to their own piece of land, women with work burden, half or less hectare of cultivable land size) also were associated with higher degree of household food insecurity, each having mean scores greater than the grand mean (8.8). The community variable (Halaba households) had higher degree of being food insecure as well as not participating in government food security programs. 
Table 4. Mean score for degree of household food insecurity by selected explanatory variables using Multiple Classification Analysis, for the two districts combined

\begin{tabular}{|c|c|c|c|c|c|}
\hline \multirow[b]{2}{*}{ Variables } & \multicolumn{4}{|c|}{ Mean score for degree of household food insecurity ${ }^{a}$} & \multirow[b]{2}{*}{ Beta $(\beta)$} \\
\hline & $\mathrm{N}$ & Unadjusted & $\operatorname{Eta}(\eta)$ & Adjusted for Factor & \\
\hline \multicolumn{6}{|c|}{ Women with access to their own piece of land } \\
\hline No & 411 & 10.25 & 0.313 & 10 & $0.25^{* * *}$ \\
\hline Yes & 152 & 5.54 & & 6.23 & \\
\hline \multicolumn{6}{|l|}{ Work burden of women ${ }^{b}$} \\
\hline No long-distance walk & 151 & 6.35 & 0.238 & 8.29 & $0.063^{* * *}$ \\
\hline Longer distance walk & 412 & 9.94 & & 9.23 & \\
\hline \multicolumn{6}{|c|}{ Number of children $<5 \mathrm{yrs}$ per household } \\
\hline One & 332 & 8.64 & 0.085 & 8.56 & $0.076^{* *}$ \\
\hline Two & 216 & 9.63 & & 9.54 & \\
\hline Three or more & 15 & 7.13 & & 10.19 & \\
\hline \multicolumn{6}{|l|}{ Physiological density ${ }^{c}$} \\
\hline 8 or less & 369 & 8.09 & 0.184 & 8.76 & $0.046^{* * *}$ \\
\hline$>8$ & 194 & 10.68 & & 9.41 & \\
\hline \multicolumn{6}{|c|}{ Cultivated land size of households } \\
\hline 0.5 or less hectare & 169 & 11.07 & 0.268 & 9.71 & $0.127^{* * *}$ \\
\hline $0.6-1.0$ hectares & 231 & 9.26 & & 9.37 & \\
\hline$>1.0$ hectares & 163 & 6.43 & & 7.67 & \\
\hline \multicolumn{6}{|c|}{ Frequency of food crop cultivation per year } \\
\hline Once & 255 & 6.72 & 0.308 & 8.43 & $0.075^{* * *}$ \\
\hline Twice & 308 & 10.85 & & 9.44 & \\
\hline \multicolumn{6}{|l|}{ Household livestock } \\
\hline Low $(0-2.5$ TLU $)$ & 309 & 10.17 & 0.237 & 9.79 & $0.135^{* * *}$ \\
\hline Average (2.5-5 TLU) & 180 & 8.37 & & 8.06 & \\
\hline $\operatorname{High}(>5$ TLU $)$ & 74 & 5.49 & & 7.82 & \\
\hline \multicolumn{6}{|l|}{ Wealth index of households } \\
\hline Low $(<4)$ & 161 & 11.07 & 0.288 & 10.16 & $0.116^{* * *}$ \\
\hline Medium (4-8) & 242 & 9.50 & & 8.71 & \\
\hline High $(>8)$ & 160 & 6.10 & & 8.20 & \\
\hline \multicolumn{6}{|l|}{ Location of community } \\
\hline Halaba & 378 & 11.26 & 0.487 & 10.75 & $0.379^{* * *}$ \\
\hline Zeway & 185 & 4.32 & & 5.36 & \\
\hline \multicolumn{6}{|c|}{ Households involvement in food security programs } \\
\hline No & 509 & 9.05 & 0.03 & 9.14 & $0.075^{* *}$ \\
\hline Yes & 54 & 8.37 & & 7.45 & \\
\hline
\end{tabular}

TLU, Tropical Livestock Unit, $1 \mathrm{TLU}=\sim 250 \mathrm{~kg}$ of livestock; ${ }^{a}$ Scores on household food insecurity access scale range from 0-27 and the higher the score, the greater the degree of food insecurity at household level; ${ }^{b}$ using the length of time required for fetching drinking water as a proxy; ${ }^{\mathrm{c}}$ the ratio of number of person in the household to the size of cultivable land in hectare; 
Table 5. Mean score for degree of household hunger by various explanatory factors using multiple classification analysis for the two districts (Halaba and Zeway) combined

\begin{tabular}{|c|c|c|c|c|c|}
\hline \multirow[t]{2}{*}{ Variables } & \multicolumn{5}{|c|}{ Mean score for degree of household hunger ${ }^{a}$} \\
\hline & $\mathrm{N}$ & Unadjusted & Eta $(\eta)$ & Adjusted for Factor & Beta $(\beta)$ \\
\hline \multicolumn{6}{|c|}{ Women with access to their own piece of land } \\
\hline No & 412 & 1.34 & 0.217 & 1.3 & $0.179^{* * *}$ \\
\hline Yes & 153 & 0.61 & & 0.71 & \\
\hline \multicolumn{6}{|l|}{ Work burden of women ${ }^{b}$} \\
\hline No long-distance walk & 151 & 0.74 & 0.163 & 1.01 & $0.06^{* *}$ \\
\hline Longer distance walk & 414 & 1.29 & & 1.19 & \\
\hline \multicolumn{6}{|c|}{ Number of children $<5$ yrs per household } \\
\hline One & 333 & 1.03 & 0.099 & 1.01 & $0.11^{*}$ \\
\hline Two & 217 & 1.33 & & 1.32 & \\
\hline Three or more & 15 & 1 & & 1.48 & \\
\hline \multicolumn{6}{|l|}{ Physiological density $^{c}$} \\
\hline 8 or less & 371 & 1.03 & 0.107 & 1.16 & 0.02 \\
\hline$>8$ & 194 & 1.36 & & 1.1 & \\
\hline \multicolumn{6}{|c|}{ Cultivated land size of households } \\
\hline 0.5 or less hectare & 169 & 1.5 & 0.203 & 1.36 & $0.126^{* *}$ \\
\hline $0.6-1.0$ hectares & 232 & 1.18 & & 1.17 & \\
\hline$>1.0$ hectares & 164 & 0.72 & & 0.87 & \\
\hline \multicolumn{6}{|c|}{ Frequency of food crop cultivation per year } \\
\hline Once & 256 & .87 & 0.166 & 1.13 & $0.009^{* *}$ \\
\hline Twice & 309 & 1.37 & & 1.15 & \\
\hline \multicolumn{6}{|l|}{ Household livestock } \\
\hline Low $(0-2.5$ TLU $)$ & 309 & 1.39 & 0.210 & 1.33 & $0.145^{* * *}$ \\
\hline Average (2.5-5 TLU) & 182 & 0.99 & & 0.95 & \\
\hline $\operatorname{High}(>5$ TLU $)$ & 74 & 0.49 & & 0.81 & \\
\hline \multicolumn{6}{|l|}{ Wealth index of households } \\
\hline Low $(<4)$ & 161 & 1.47 & 0.191 & 1.3 & 0.068 \\
\hline Medium (4-8) & 243 & 1.19 & & 1.07 & \\
\hline $\operatorname{High}(>8)$ & 161 & 0.73 & & 1.09 & \\
\hline \multicolumn{6}{|l|}{ Location of community } \\
\hline Halaba & 378 & 1.47 & 0.313 & 1.4 & $0.253^{* * *}$ \\
\hline Zeway & 187 & 0.48 & & 0.61 & \\
\hline \multicolumn{6}{|c|}{ Households involvement in food security programs } \\
\hline No & 511 & 1.15 & 0.019 & 1.16 & 0.045 \\
\hline Yes & 54 & 1.06 & & 0.94 & \\
\hline
\end{tabular}

TLU, Tropical Livestock Unit, 1TLU $=\sim 250 \mathrm{~kg}$ livestock; ${ }^{a}$ Scores on household hunger scale range from $0-6$ and the higher the score, the greater the chance of experiencing household hunger; ${ }^{\mathrm{b}}$ using the length of time required for fetching drinking water as a proxy; ${ }^{\mathrm{c}}$ the ratio of number of person in the household to the size of cultivable land in hectare.

Most of these factors also significantly predicted the degree of experiencing household hunger (a more severe condition of food insecurity) (Table 5). The model itself explained considerable variation in the dependent variable (i.e. mean scores for degree of household hunger) and was very significant $[F(14)=9.884, p<0.001$; $\left.\mathrm{R}^{2}=0.201\right]$. Demand side factors such as household TLU and number of children under 5yrs of age per household were significant in the model, after adjustment for all other factors. Likewise, supply side factors, such as women's access to land, work burden on women, cultivable land size and frequency of production per year were significant predictors. The community variable (i.e. Halaba) was associated with higher risk of experiencing household hunger.

\section{Discussion}

We found that the overwhelming majority of participant households from either community were food insecure and nearly one in every three households in the combined data experienced moderate to severe household hunger. Halaba was significantly worse than Zeway on both scales. We also found that most of the selected supply and demand side factors, as well as the community and institutional factors significantly predicted household food insecurity and hunger in the pooled data; however, the combined supply factors (i.e. women's access to own piece of land, cultivable land size of the household, work burden on women, frequency of crop harvest per year) appeared to have greater influence on both food insecurity and hunger. 
Roba et al. (Roba et al., 2015) also found very high level of household food insecurity (87\%) in a 2011 study that examined adolescent nutrition in the Halaba district. However, the proportion of households we reported as severely food insecure (63\%) were much higher compared with only $16 \%$ reported by Roba et al. This difference may have been due to timing of data collection - i.e. how soon or late data were collected after main harvest season ( Oct-Dec) in the district (FAO, 2015). We collected data during the months of March-June whereas Roba et al. (2015) collected in February-March. Therefore, our finding of more households with severe food insecurity may indicate limited food supply or economic inability to access food, and hence increased risk of household food insecurity in the months further away from harvest season.

In an adjacent rural district, Regassa and Stoecker (2012) reported high levels (82\% and 29\%) of household food insecurity and hunger, respectively, although the study was conducted during December-January period, i.e. closer to crop harvest compared to ours (March-June). The vulnerability of households to food shortage and hunger, even shortly after main harvest, may indicate insufficient harvest due to poor productivity which itself arises from a combination of factors such as application of inadequate farm input (improved seed/fertilizer), dependence on climate change induced erratic rain fall, low irrigation use (FAO, 2015), a tenure policy that enforce state control of land and discourages sustainable investment by farmers on the land (Crewett, Bogale, \& Korf, 2008; Nega, Adenew, \& Gebre Sellasie, 2003) and small land holding size, arising from a geometric increase in population growth (Sewnet, 2015). For example, $70 \%$ of our study households reported a $<1$ ha land holding but with high $(6 \pm 2)$ average family size (Table 1). However, high prevalence of food insecurity is not limited to rural farming households as studies have shown similar trends in urban settings both in Ethiopia (Birhane et al., 2014; Endale et al., 2014) and in neighbouring Kenya (Kimani-Murage et al., 2014; Shinsugi et al., 2015).

As indicated by several studies in Ethiopia (Ali et al., 2013; Belachew, Lindstrom, Gebremariam, et al., 2013; Belachew, Lindstrom, Hadley, et al., 2013; Roba et al., 2015) and elsewhere (McDonald et al., 2015; Shinsugi et al., 2015; Young et al., 2014), household food insecurity, and the subsequent hunger, is one of the underlying causes of poor nutritional health outcomes in vulnerable household members. However, household food insecurity (and hunger) or food security itself is a function of social-economic, demographic, environmental and policy related factors interacting at national, regional, community or household levels, as outlined in the well-known 'conceptual framework of malnutrition' by UNICEF (UNICEF, 1990). In our study, we investigated a select group of some of these factors, conceptually organized as demand or supply, as well as community and institutional factors, and measured their effect on food insecurity and hunger at household level. Supply side factors [women's access to land, household land-size, frequency of production per year and work burden of women] were significant predictors of food insecurity and hunger both in the bivariate (unadjusted) and multivariate (adjusted for factors) analysis (Tables $4 \& 5$ ). Households where women had no access to their own farm land, traveled longer distances to fetch water (work burden) and households that had small land size ( $\leq 5 \mathrm{ha})$ and produced crops twice per year had significantly higher mean scores on HFIAS \& HHS scales $(p<0.001)$, indicating greater degree of food insecurity and hunger in these households. The direction of association of all supply side factors to food insecurity and hunger was as expected except 'frequency of crop production per year' in which more than once/year crop production did not appear to reduce vulnerability to food insecurity or hunger in both the adjusted and unadjusted models. This may indicate perhaps improving productivity is more important than the frequency of production. However further research is required to establish the exact scenario.

Land size is an important resource that determines food supply in communities that depend on farming as main livelihood. However, since most households in Ethiopia have smaller farmland due to the high population growth (Sewnet, 2015), increasing productivity per unit of land area is the next feasible option to ensure sufficient food supply for households. This, in turn, requires a labour force where women play a key role. The FAO and World Bank reports on the role of women in agriculture states that the goal of feeding the world cannot be realized without the contribution of women that make up significant part of the labour force (FAO, 2011, 2012; World Bank/FAO/IFAD, 2009). Likewise, Mosse (Mosse, 1993), also emphasized the significant contribution of women in agriculture or any development. We showed households where women spend significant time going longer distances to fetch water had increased risk for household food insecurity $(p<0.001)$.

Lack of access to land by women was also an important predictor of food insecurity and hunger $(p<0.001)$ where households in which women had their own piece of farm land had significantly lower scores (i.e. lower risk of being food insecure or experiencing hunger). This may be due to the relative flexibility women with access to land have to make decisions on their produce whether to consume at home or sell. Allendorf (Allendorf, 2007) has shown that women with access to land had better decision making power at household levels and provided better care for children. Therefore, policies that minimize or eliminate the gender disparities in equal access to 
land should be put in effect.

From demand side factors, we identified households with the lowest livestock, in the lowest wealth category, with two or more children under 5yrs of age and higher physiological density were at greater risk for food insecurity. Since physiological density is a function of land (limited resource) and household size, improving productivity of land and strengthening family planning services could assist efforts toward household food security. The geographic location of study communities was also a strong predictor; households from Halaba were twice as likely to experience food insecurity and hunger as those from Zeway. Other community level factors that were not captured in this study, such as market proximity, aggregate food supply, cultural beliefs/food taboos, history of susceptibility to drought, community level coping mechanism, may have contributed to the observed location difference in vulnerability, warranting further investigation. Households' involvement in the local food insecurity programs (institutional variable) showed that those who did not participate had greater chance of experiencing food insecurity and hunger. We did not, however, ask why households did not participate in programs despite the high prevalence of food insecurity and hunger in the area. Future studies to investigate whether the limited involvement in food security programs was due to lack of service coverage or refusal from the side of households are required.

While the above micro-level factors explained $41 \%\left(\mathrm{R}^{2}=0.405\right)$ the variation in the outcome variable, a great deal of remaining variation may be explained by other macro level variables such as, policies that affect aggregate food supply, which were not captured in our model. One of such policy would be one that deals with land. The fact that about $80 \%$ of Ethiopia's population depends on agriculture makes land a key resource. Hence government policies on land administration (i.e. ownership, certification, transfer and women's access to land) affect food production and the subsequent household food security status. In Ethiopia, farmers have only usufruct right to land while the state owns the land (Crewett et al., 2008; Nega et al., 2003) which may raise concerns on the issue of food sovereignty. Food sovereignty, which pertains to the right of farmers to decide on their own production, distribution and marketing of food as well as ownership of farm land, is a bigger concept than food security (Cochrane, 2011). It advocates not just achieving food security, which places much emphasis on food availability and access without regard to the source of the food (imported verses local), but that farmers should own and decide on the process of achieving food security. Lack of land tenure security may significantly impact productivity and the subsequent household food supply as it may prevent farmers from fully investing on the land as though it were their own. The existing land policy also allows the government of Ethiopia to lease land to foreign investors. Some have criticized this leasing of land to foreign investors and referred it as "land grabbing" (Cochrane, 2011; Settee, 1999; The Oakland Institute, 2015) as the process has resulted in the eviction of indigenous people from their farm or pastoral land in parts of southern Ethiopia. In recent years, the government has started implementing a land certification policy that aimed at benefiting female headed households and married women to improve their access and control of land thereby empowering them (UN-HABITAT, 2008). Some studies and practical experiences (Settee, 1999) also suggest that ensuring land right provides more benefits when local governments promote indigenous knowledge and practices, such as preservation of community's natural environment to ensure sustainable food systems at community and household levels.

At a bigger scale, Ethiopia continues to face a significant challenge in achieving food security at the household and individual level. The 2014 Global Hunger Index (GHI) study ranked Ethiopia among the bottom countries with severe levels (24.4\%) of global hunger (Grebmer et al., 2014). The index is an average measurement of three indicators: undernourished population (\% with insufficient caloric intake), prevalence of underweight children and level of child mortality before $5^{\text {th }}$ birthday. Based on GHI classification, the severity of the observed hunger in Ethiopia was set as 'alarming'. In 2015, Ethiopia was faced with severe drought in parts of the country due to lack of rain and the food security situation has significantly deteriorated as 8.2 million people were food insecure by October (double the number from previous year in the same period) (FAO, 2015). This also affirms the presence of a challenging food environment for vulnerable household members in the country, requiring systematic and aggressive efforts to tackle the problem at household, community and policy levels.

The limitation of our study was it failed to provide a full picture on the pattern of food insecurity on a different season in either districts due to cross-sectional nature of the design. We also did not collect detailed information on farming practices, use of technology (improved seed, fertilizer, and farming techniques), and market access. which might help explain why producing crops twice per year did not reduce vulnerability to food insecurity or hunger. We recommend further study to explore these factors and also the actual dietary intakes and overall consumption pattern of vulnerable family members, such as mothers, children and adolescent girls, to estimate the level of risk of inadequacy for programmatic purposes. 


\section{Conclusion}

In this study, we reported that household food insecurity was unacceptably high in both districts $95 \%$ in Halaba and $67 \%$ in Zeway). Household hunger was $38 \%$ in Halaba and $18 \%$ in Zeway. Both food insecurity and hunger were significantly greater in Halaba $(\mathrm{p}<0.001)$, warranting large scale investigation into the farming system factors. Both supply and demand factors were significant in determining household food insecurity and hunger $(p<0.01)$; however, supply factors such as women's access to land, land size, frequency of production and work burden had greater influence than the demand factors. Levels of food insecurity and hunger in both communities were very high and of serious concern. We recommend increasing the food supply, and its subsequent accessibility, for households by improving productivity of cultivable land, enhancing women's access to land, augmenting income through savings and wealth accumulation, introducing more inclusive programs for women, and reducing their work burden.

\section{Acknowledgements}

The authors appreciate research participants and data collectors. International Development Research Centre (IDRC) and Global Affairs Canada, Government of Canada, through the Canadian International Food Security Research Fund (CIFSRF) supported the field research.

\section{References}

Alem, H. (2013). Rural households' transitory food insecurity and Coping strategies in Ethiopia Highland. Paper presented at the Sixth International Conference on Agricultural Statistics (ICAS VI), Rio De Janeiro, Brazil. http://eventos.ibge.gov.br/en/icas2013/programa-da-conferencia/sessao-de-poster\#

Ali, D., Saha, K. K., Nguyen, P. H., Diressie, M. T., Ruel, M. T., Menon, P., \& Rawat, R. (2013). Household food insecurity is associated with higher child undernutrition in Bangladesh, Ethiopia, and Vietnam, but the effect is not mediated by child dietary diversity. $J$ Nutr., 143(12), 2015-2021.

Allendorf, K. (2007). Do Women's Land Rights Promote Empowerment and Child Health in Nepal?. World Dev, 35(11), 1975-1988. https://doi.org/10.1016/j.worlddev.2006.12.005

Anderson, L. C., Tegegn, A., Tessema, F., Galea, S., \& Hadley, C. (2012). Food insecurity, childhood illness and maternal emotional distress in Ethiopia. Public Health Nutr., 15(4), 648-655. https://doi.org/10.1017/S1368980011001340

Belachew, T., Lindstrom, D., Gebremariam, A., Hogan, D., Lachat, C., Huybregts, L., \& Kolsteren, P. (2013). Food insecurity, food based coping strategies and suboptimal dietary practices of adolescents in Jimma zone Southwest Ethiopia. PloS one, 8(3), e57643. https://doi.org/10.1371/journal.pone.0057643

Belachew, T., Lindstrom, D., Gebremariam, A., Jira, C., Hattori, M. K., Lachat, C., ... Kolsteren, P. (2012). Predictors of chronic food insecurity among adolescents in Southwest Ethiopia: a longitudinal study. BMC Public Health, 12, 604-2458-2412-2604.

Belachew, T., Lindstrom, D., Hadley, C., Gebremariam, A., Kasahun, W., \& Kolsteren, P. (2013). Food insecurity and linear growth of adolescents in Jimma Zone, Southwest Ethiopia. Nutrition journal, 10, 29. https://doi.org/10.1186/1475-2891-10-29

Birhane, T., Shiferaw, S., Hagos, S., \& Mohindra, K. S. (2014). Urban food insecurity in the context of high food prices: a community based cross sectional study in Addis Ababa, Ethiopia. BMC Public Health, 14, 680. https://doi.org/10.1186/1471-2458-14-680

BOWYCA. (2013). Situational analysis of boys and girls in SNNPR: a rights-based approach. Hawassa, Ethiopia: Bureau of Women Youth and Children Affares (BOWYCA).

Central Statistical Agency [Ethiopia] and ICF International. (2012). Ethiopia Demographic and Health Survey 2011. Addis Ababa, Ethiopia and Calverton, Maryland, USA: http://dhsprogram.com/pubs/pdf/FR255/FR255.pdf

Central Statistical Agency [of Ethiopia]. (2015). Key Findings of the 2014/2015 (2007 E.C.) Agricultural Sample Surveys: Country Summary. Addis Ababa, Ethiopia: The Federal Democratic Republic of Ethiopia, Central Statistics Agency.

Charan, J., \& Biswas, T. (2013). How to calculate sample size for different study designs in medical research? Indian J Psychol Med, 35(2), 121-126. https://doi.org/10.4103/0253-7176.116232

Coates, J., Swindale, A., \& Bilinsky, P. (2007). Household Food Insecurity Access Scale (HFIAS) for Measurement of Household Food Access: Indicator Guide (v. 3). Retrieved from 
http://www.fantaproject.org/downloads/pdfs/HFIAS_v3_Aug07.pdf

Cochrane, L. (2011). Food Security or Food Sovereignty: The Case of Land Grabs The Journal of Humanitarian Assistance.

Crewett, W., Bogale, A., \& Korf, B. (2008). Land Tenure in Ethiopia: Continuity and Change, Shifting Rulers, and the Quest for State Control. CAPRi Working Paper 91. Retrieved from http://ebrary.ifpri.org/cdm/ref/collection/p15738coll2/id/24652

Deitchler, M., Ballard, T., Swindale, A., \& Coates, J. (2010). Validation of a Measure of Household Hunger for Cross-Cultural Use. Washington, DC: Retrieved from http://www.fantaproject.org/sites/default/files/resources/HHS_Validation_Report_May2010_0.pdf

Deitchler, M., Ballard, T., Swindale, A., \& Coates, J. (2011). Introducing a simple measure of household hunger for cross-cultural use. Retrieved from http://www.fao.org/fileadmin/user_upload/wa_workshop/docs/HH_Hunger_Scale.pdf

Devereux, S. (2000). Food Insecurity in Ethiopia: A discussion paper for DFID. Retrieved from https://www.ids.ac.uk/files/FoodSecEthiopia4.pdf

EHNRI (Ethiopia Health and Nutrition Reaserch Institute). (2010). Nutrition baseline survey report for the National Nutrition Program of Ethiopia. Addis Ababa, Ethiopia.

Endale, W., Mengesha, Z. B., Atinafu, A., \& Adane, A. A. (2014). Food insecurity in Farta District, Northwest Ethiopia: a community based cross-sectional study. BMC research notes, 7, 130. https://doi.org/10.1186/1756-0500-7-130

Endalew, B., Muche, M., \& Tadesse, S. (2015). Assessment of Food Security Situation in Ethiopia: A Review. Asian Journal of Agricultural Research, 9, 55-68. https://doi.org/10.3923/ajar.2015.55.68

FAO. (1996). Rome Declaration on World Food Security and World Food Summit Plan of Action: World Food Submit 13-17 November 1996 Retrieved from Rome: http://www.fao.org/docrep/003/w3613e/w3613e00.HTM

FAO. (2011). The State of Food and Agriculture 2010-2011: Women in Agriculture, Closing the Gender Gap for Development Retrieved from http://www.fao.org/docrep/013/i2050e/i2050e.pdf

FAO. (2012). Gender and Nutrition - DRAFT. Retrieved from http://www.fao.org/fileadmin/user_upload/wa_workshop/docs/Gender-Nutrition_FAO_IssuePaper_Draft.pd $\mathrm{f}$

FAO. (2015). Global Information and Early Warning System on Food and Agriculture: Ethiopia Country Brief. Food and Agriculture Organization of the United Natioins.

Feleke, S. T., Kilmer, R. L., \& Gladwin, C. H. (2005). Determinants of food security in Southern Ethiopia at the household level. Agricultural Economics, 33, 351-363. https://doi.org/10.1111/j.1574-0864.2005.00074.x

Grebmer, K. V., Saltzman, A., Birol, E., Wiesmann, D., Prasai, N., Yin, S., ... Sonntag, A. (2014). 2014 Global Hunger Index: The Challenge of Hidden Hunger. Retrieved from Bonn, Washington, D.C. and Dublin: http://reliefweb.int/sites/reliefweb.int/files/resources/ghi14.pdf

Hadley, C., Tessema, F., \& Muluneh, A. T. (2012). Household food insecurity and caregiver distress: equal threats to child nutritional status? Am J Hum Biol, 24(2), 149-157. https://doi.org/10.1002/ajhb.22200

Kimani-Murage, E. W., Schofield, L., Wekesah, F., Mohamed, S., Mberu, B., Ettarh, R., ... Ezeh, A. (2014). Vulnerability to food insecurity in urban slums: experiences from Nairobi, Kenya. J Urban Health, 91(6), 1098-1113. https://doi.org/10.1007/s11524-014-9894-3

McDonald, C. M., McLean, J., Kroeun, H., Talukder, A., Lynd, L. D., \& Green, T. J. (2015). Household food insecurity and dietary diversity as correlates of maternal and child undernutrition in rural Cambodia. Eur $J$ Clin Nutr, 69(2), 242-246. https://doi.org/10.1038/ejen.2014.161

Mosse, J. C. (1993). Half the World Half a Chance: An introduction to gender and evelopment. Oxford: Oxfam. https://doi.org/10.3362/9780855987633

Nagpaul, P. S. (1999). Guide to Advanced Data Analysis Using IDAMS Software. Retrieved from http://www.unesco.org/webworld/idams/advguide/TOC.htm

Nega, B., Adenew, B., \& Gebre Sellasie, S. (2003). Current Land Policy Issues in Ethiopia. In P. Groppo (Ed.), 2003/3 Land Reform: Land Settlement and Cooperatives- Special Edition. Rome, Italy FAO \& World Bank. 
Regassa, N. (2011). Small holder farmers coping strategies to household food insecurity and hunger in Southern Ethiopia. Ethiopian Journal of Environmental Studies and Management, 4(1). https://doi.org/10.4314/ejesm.v4i1.5

Regassa, N., \& Stoecker, B. J. (2012). Household food insecurity and hunger among households in Sidama district, southern Ethiopia. Public Health Nutr, 15(7), 1276-1283. https://doi.org/10.1017/S1368980011003119

Roba, A. C., Gabriel-Micheal, K., Zello, G. A., Jaffe, J., Whiting, S. J., \& Henry, C. J. (2015). A low pulse food intake may contribute to the poor nutritional status and low dietary intakes of adolescent girls in rural southern ethiopia. Ecol Food Nutr, 54(3), 240-254. https://doi.org/10.1080/03670244.2014.974593

Settee, P. (1999). Honouring Indigenous Science as a Means of Ensuring Scientific Responsibility (Master of Education ), University of Manitoba, Winnipeg, Manitoba. Retrieved from http://sap-water-project.ca/sites/default/files/myDocuments/Honouring-Indigenous-Knowledge.pdf

Sewnet, Y. (2015). Causes and coping mechanisms of food insecurity in rural Ethiopia. Agric. Biol. J. N. Am., 6(5), 123-133.

Shinsugi, C., Matsumura, M., Karama, M., Tanaka, J., Changoma, M., \& Kaneko, S. (2015). Factors associated with stunting among children according to the level of food insecurity in the household: a cross-sectional study in a rural community of Southeastern Kenya. BMC Public Health, 15(1), 441. https://doi.org/10.1186/s12889-015-1802-6

Smith, M., Pointing, J., \& Maxwell, S. (1992). Household food security, concepts and definitions: An Annotated Bibliography. In S. Maxwell \& T. R. Frankerberger (Eds.), Household Food Security: Concepts, Indicators, Measurements- A Technical Review. New York and Rome: United Nation's Children's Fund - International Fund for Agricultural Development.

Storck, H., Emana, B., Adinew, B., Borowiecki, A., \& W/Hawariat, S. (1991). Farming systems and farm management practices of smallholders in the Hararghe Highlands. In Farming systems and Resource Economics in the Tropics (Vol. 11). F.R, Germany: Wissenschaftsverlag, Vauk, Kiel.

Tessema, M., Belachew, T., \& Ersino, G. (2013). Feeding patterns and stunting during early childhood in rural communities of Sidama, South Ethiopia. Pan Afr Med J., 14, 75.

The Oakland Institute. (2015). We say the land is not yours: Breaking the silence against forced displacement in Ethiopia. Oakland, CA, The Oakland Institute. Retrieved from http://www.oaklandinstitute.org/sites/oaklandinstitute.org/files/Breaking\%20the\%20Silence.pdf

UN-HABITAT. (2008). Land registration in Ethiopia: Early impacts on women. Retrieved from http://siteresources.worldbank.org/NEWS/Resources/land_eegistration_in_ethiopia.pdf

UNICEF. (1990). Strategy for Improved Nutrition of Children and Women in Developing Countries: a UNICEF Policy Review. Retrieved from http://www.ceecis.org/iodine/01_global/01_pl/01_01_other_1992_unicef.pdf

WHO, \& UNICEF. (2010). Progress on Sanitation and Drinking-water: 2010 update (978 924156395 6). Geneva: World Health Organization (WHO) and United Nation Children's Fund (UNICEF).

World Bank/FAO/IFAD. (2009). Gender in Agriculture: SourceBook. Washington, D.C.: The International Bank for Reconstruction and Development /The World Bank.

Young, S. L., Plenty, A. H., Luwedde, F. A., Natamba, B. K., Natureeba, P., Achan, J., ... Cohan, D. L. (2014). Household food insecurity, maternal nutritional status, and infant feeding practices among HIV-infected Ugandan women receiving combination antiretroviral therapy. Matern Child Health J., 18(9), 2044-2053.

\section{Notes}

Note 1. Ensete ventricosum, also known as false banana, is the most common starchy staple and important food security crop in the southern parts of Ethiopia.

\section{Copyrights}

Copyright for this article is retained by the author(s), with first publication rights granted to the journal.

This is an open-access article distributed under the terms and conditions of the Creative Commons Attribution license (http://creativecommons.org/licenses/by/4.0/). 